\title{
CREENCIAS RELIGIOSAS VERSUS GESTIÓN DEL PATRIMONIO ARQUEOLÓGICO: EL CASO DEL CEMENTERIO JUDÍO DE VALENCIA
}

\author{
RELIGIOUS BELIEVES VERSUS CULTURAL RESOURCE MANAGEMENT: \\ ABOUT THE MEDIEVAL JEWISH CEMETERY OF VALENCIA (SPAIN)
}

\author{
JOSÉ LUIS JIMÉNEZ (*) \\ CONSUELO MATA $(*)$
}

\section{RESUMEN}

La propiedad sobre el patrimonio histórico es objeto de controversia al amparo de reivindicaciones de tipo étnico o religioso. En 1996, diversas Comunidades Judías consiguieron paralizar la excavación arqueológica de un importante sector de la necrópolis judía medieval de Valencia e impidieron la investigación arqueológica de los restos humanos descubiertos que fueron reinhumados en el actual cementerio judío de Barcelona. Los gobiernos local y autonómico antepusieron las exigencias religiosas de las Comunidades Judías al respeto hacia el patrimonio arqueológico. A raíz de una queja formulada por un grupo de ciudadanos, el Síndic de Greuges (Síndico de Agravios) de la Comunidad Valenciana dictó una resolución condenatoria sobre la decisión tomada por los poderes públicos.

\begin{abstract}
Archaeological heritage ownership is a controversial subject under the influence of both ethnic and religious claims. In 1996, a group of Jewish communities finally were able to interrupt the archaeological excavation under way at the medieval Jewish cemetery of Valencia. In this manner they did not allow the anthropological analysis of $h u$ man remains recovered at the site that were reburied at the Jewish cemetery of Barcelona. Both administrations, local and regional, prioritized religious claims of the communi-
\end{abstract}

(*) Dept. Prehistòria i Arqueologia. Universitat de València Av. Blasco Ibáñez 28, 46010 València. España. Correo electrónico: Jose.L.Jimenez@uv.es; Consuelo.Mata@uv.es

El artículo fue remitido en su versión final el 25-VI-2001. ties involved with respect to the archaeological heritage. As a consequence of a complaint filed by a group of citizens, the Síndic of Greuges of the Valencian Community (regional ombudsman) signed a condemnatory resolution against the initial resolution of the public administration.

Palabras claves: Reinhumación. Gestión del patrimonio arqueológico. Religión. Legislación. Cementerio judío. Edad Media. Valencia.

Key words: Re-inhumation. Archaeological resource management. Religion. Legislation. Jewish cemetery. Medieval Age. Valencia.

\section{INTRODUCCIÓN}

La Constitución Española de 1978 en su art. 46 señala que los poderes públicos garantizarán la conservación y promoverán el enriquecimiento del patrimonio histórico, cultural y artístico de los pueblos de España y de los bienes que lo integran, cualquiera que sea su régimen jurídico y su titularidad. El caso que traemos a colación en el presente artículo viene a demostrar que el cumplimiento de este mandato constitucional no siempre se lleva a término, sobre todo cuando se enfrenta a situaciones en las que, por razones de índole étnica o religiosa, se reivindica la propiedad de determinado patrimonio cultural; un fenómeno que en los últimos años viene manifestándose de manera creciente y a escala mundial (Endere, 2000). En este caso, se trata de algo acontecido hace apenas un lustro en la ciudad de Valencia, y que reviste especial gravedad por las consecuencias derivadas de una gestión negligen- 


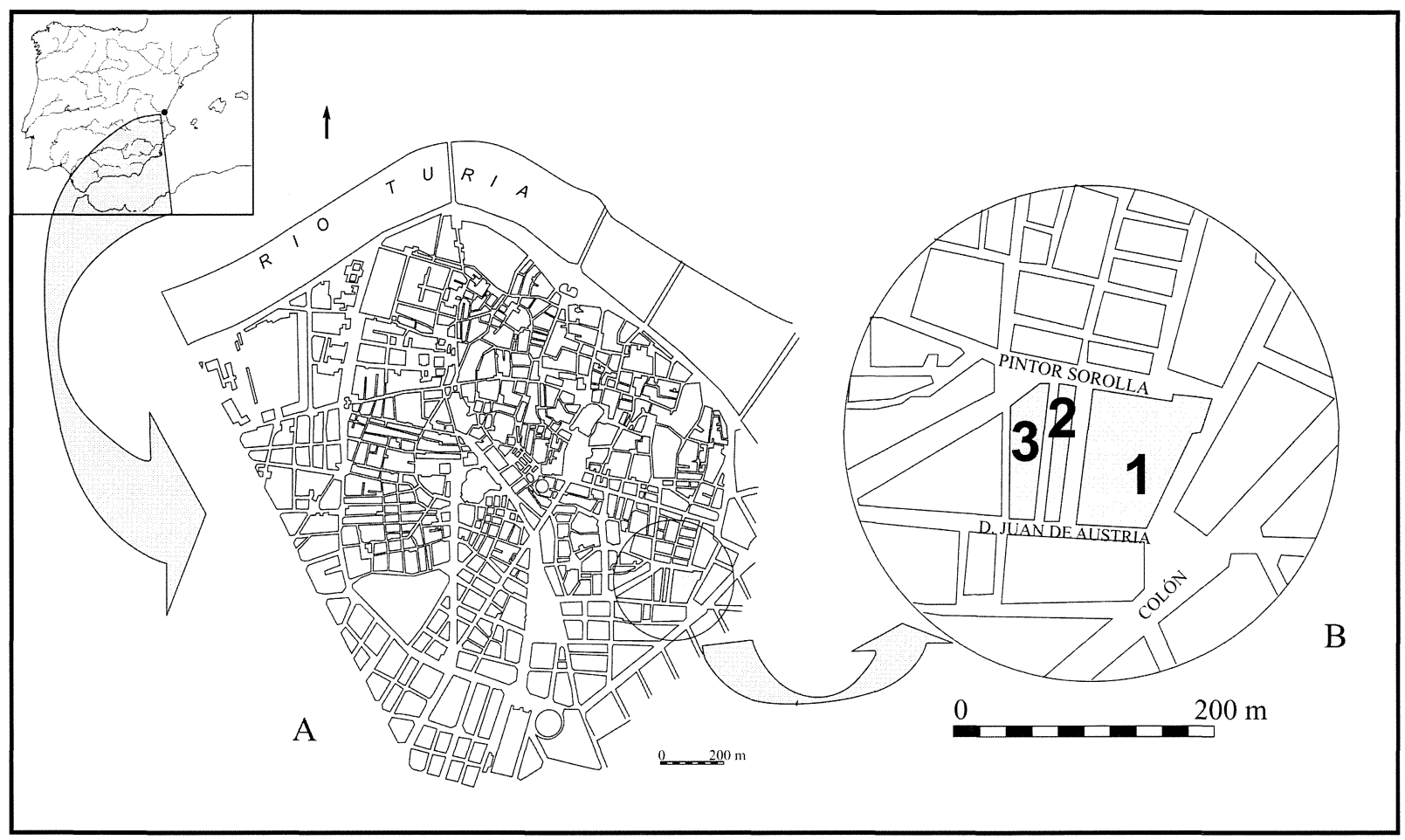

Fig. 1. Emplazamiento de la ciudad de Valencia.A, Centro histórico; B, Ampliación de la zona donde se han localizado restos del cementerio judío (con trama gris): 1, Edificio de grandes almacenes; 2, Excavación de la c/ Monjas de Santa Catalina; 3, Excavación de la c/ Doctor Romagosa.

te del patrimonio arqueológico por parte de las administraciones autonómica y local que optaron por cercenar una investigación arqueológica planificada en toda regla, como era la excavación de un importante sector de la necrópolis judía medieval, anteponiendo las exigencias de la actual comunidad hebrea al cumplimiento de la legislación vigente.

Resulta paradójico que la primera excavación con finalidad arqueológica en la ciudad de Valencia fuera acometida en 1890 en la calle Cirilo Amorós, como consecuencia del hallazgo casual de lo que parecían ser varias tumbas judías, que fueron excavadas y dibujadas por la Delegación Municipal de Monumentos (Ribera, 1998: 13-14), y que un siglo más tarde, se haya sustraído una documentación arqueológica esencial para la reconstrucción histórica de la ciudad. Este artículo pretende servir de elemento de reflexión acerca del papel desempeñado por las administraciones públicas en el cumplimiento de la legislación vigente y que con ejemplos como el aquí expuesto, se demuestra que, con más frecuencia de la deseada, los poderes públicos son los primeros en volver la espalda a la legislación. Ante situaciones como la registrada en Valencia, la pregunta es inevitable: $¿$ a quién pertenece el patrimonio histórico?

\section{UNA INVESTIGACIÓN ARQUEOLÓGICA TRUNCADA}

La necrópolis de la aljama hebrea de Valencia se emplazaba al SE de la "Juheria", en un principio en las afueras del recinto amurallado islámico y desde 1356, en el interior de la nueva trama urbana resultante de la construcción de la muralla cristiana en el transcurso de la contienda entablada entre Pedro I el Cruel de Castilla y Pedro IV el Ceremonioso de Aragón (1). Su perímetro estaba delimitado por las actuales calles de Colón, Pintor Sorolla, Doctor Romagosa y Don Juan de Austria (Fig.1 B). Esta necrópolis quedó amortizada por varias fosasbasurero de la primera mitad del siglo $\mathrm{XV}$, quizás a resultas del asalto sufrido por la Judería de Valencia en 1391. A consecuencia de este hecho violen-

(1) Calvo, M. (2000): La investigación arqueológica sobre la necrópolis judía de Valencia. Campañas 1993-1994. Tesis de Licenciatura, Universitat de València, València (inédita). 
to, la comunidad judía desapareció desde el punto de vista jurídico y legal. Su recuerdo quedaría plasmado en una de las doce puertas y portales que daban acceso al espacio intramuros, denominada "Portal dels Juheus", de la que podemos hacernos una idea de sus dos torreones cuadrados gracias a un dibujo realizado porWijngaerde en 1563 (Teixidor, 1990: 53-54) (Fig. 2, 1-2).

Diversos testimonios avalan la existencia de la Judería (Rodrigo, 1913; Pérez Herrero, 1978; Lacave, 1987; 1991, 33; Roca, 1998; Hinojosa, 1999; cft. nota 1). Sobre su desaparición, Cock en su obra Relación del viaje hecho por Felipe II en 1585, á Zaragoza, Barcelona y Valencia, constata la transformación, en 1391, de la sinagoga en Iglesia de San Cristóbal y Teixidor, en el tomo I de sus Antigüedades deValencia (1767), alude a que sobre el cementerio de los judíos se fundó en 1491, el convento de Santa Catalina de Siena (Fig. 2, 2 y 4). En 1970, la iglesia de este convento fue desmontada y trasladada piedra a piedra hasta el barrio de Orriols para permitir la construcción de unos grandes almacenes; obras que se llevaron a cabo sin control arqueológico alguno, a pesar de que desde el siglo XVI se tenía constancia de que la zona pertenecía a la Judería (Ribera, 1995: 281).

A raíz del establecimiento de los primeros ayuntamientos democráticos en 1979, la ciudad de Valencia se dotó de una serie de instrumentos de protección de su patrimonio histórico. Así, en el marco del Plan General de Ordenación Urbana, aprobado en 1988, se elaboraron unos Planes Especiales de Protección del Centro Histórico, que incluyeron una serie de apartados referidos al patrimonio arqueológico de la ciudad (Ribera, 1989). En virtud de ellos, se establecía un área de protección coincidente con el casco antiguo, delimitado por las murallas del siglo XIV que abarcaban las ciudades romana y medieval (Fig. 1 A). Como quiera que la necrópolis judía estaba incluida dentro del recinto medieval, ésta recibía la consideración de zona de ProtecciónArqueológica, lo que implicaba la necesidad de realizar el preceptivo informe arqueológico previo a cualquier remoción de tierras en dicha zona (Fig. 1, B).

Fue así como en octubre- noviembre de 1993 y en un solar contiguo al lugar de los primeros hallazgos, el ${ }^{\circ} 4$ de la calle Monjas de Santa Catalina, se realizó una excavación arqueológica, a la que siguió otra entre los meses de abril y agosto de 1994, en otro solar delimitado por las calles Bisbe y Monjas de Santa Catalina (Calvo y Lerma, 1996: 261-275; cft. nota 1) (Fig.1, B), confirmándose la importancia arqueológica de esta zona (Calvo y Lerma, 1998: 50-59). Estos trabajos darían paso a una tercera campaña de excavación en enero de 1996 en un solar de la calle Doctor Romagosa con una duración prevista de tres meses, que se vería afectada por la solicitud de paralización de las labores arqueológicas (Fig. 1, B). Esta petición en un principio fue formulada por la Comunidad Judía deValencia (Las Provincias, 8/2/96), a la que pronto se sumaría la Federación de Comunidades Israelitas en España. A partir de este momento, se produce una cadena de hechos protagonizados por las citadas comunidades judías junto con la Embajada de Israel en España, el Ministerio de Justicia, la Generalitat Valenciana y el Ayuntamiento deValencia. Finalmente, la Federación de Comunidades Israelitas en España exige a las administraciones autonómica y local que los restos esqueléticos no sean objeto de manipulación alguna, impidiéndose cualquier tipo de análisis, y que sean reinhumados en un cementerio judío próximo. ElAyuntamiento de Valencia y la Conselleria de Cultura, Educació i Ciència de la Generalitat Valenciana autorizan el traslado de los cuerpos al cementerio judío de Barcelona sin haber podido realizarse los análisis que se efectúan a los huesos humanos de cualquier excavación arqueológica. Este traslado se hizo extensivo también a los procedentes de campañas anteriores que, hasta ese momento, no habían suscitado reivindicación alguna.

Desde el comienzo de la campaña de excavación en enero de 1996 hasta llegar a la exhumación de los restos y su traslado al cementerio judío de Barcelona, que tuvo lugar el día 18 de abril del mismo año, los acontecimientos se sucedieron con gran rapidez. Un brevísimo relato de los hechos comenzaría cuando al poco de iniciada la nueva campaña de excavación arqueológica, la Comunidad Judía valenciana manifiesta, a través de su presidente, Samuel Sefarti, su interés por los descubrimientos que los medios de comunicación, sobre todo prensa escrita local, empiezan a difundir, destacando la importancia de estos hallazgos para el conocimiento de la Judería de Valencia, al proceder de la excavación en extensión de un solar de considerable superficie en el que se había autorizado la construcción de un edificio de cinco pisos y tres plantas de garaje.

A comienzos de marzo de 1996, el Ministerio de Justicia solicita al Ayuntamiento de Valencia que se dé una solución a este problema en colaboración con la Comunidad Judía. Por su parte, la Federación

T. P., 58, n. $^{\circ} 2,2001$ 
de Comunidades Israelitas de España, por boca de su presidente, Carlos Schorr, se muestra tajante a la hora de solicitar la paralización de los trabajos de excavación arqueológica y la suspensión de la correspondiente licencia de obras, así como de cualquier tipo de análisis sobre los 92 esqueletos hallados (Levante-EMV, 15/3/96; Las Provincias, 21/3/ 96). Se da la paradoja de que al mismo tiempo que se está negando la posibilidad de efectuar estudio alguno sobre los mismos, un representante de la Comunidad Judía de Valencia, Agustín Andreu, que a su vez ostentaba el cargo de Director del extinto Institut Valencià d'Estudis e Investigació, dependiente de la Generalitat Valenciana y de la Diputación Provincial de Valencia, tiene previsto crear una asociación dedicada al estudio de la cultura hebrea en España (Las Provincias, 13/3/96).

A continuación, se entra en un rocambolesco proceso de negociación en el que el Ayuntamiento de Valencia pretende alcanzar algún tipo de acuerdo con la Comunidad Judía en virtud del cual se autorizaría el traslado de los restos exhumados, incluidos los 66 esqueletos recuperados en la campaña de 1993, a cambio de conservar algunos para su estudio arqueológico (Levante-EMV, 26/3/96). El 31 de marzo finaliza el plazo previsto para la excavación arqueológica sin que el equipo investigador haya podido concluir sus labores. Como la empresa constructora dispone de una licencia de obra condicionada al término de las excavaciones, el Ayuntamiento negocia con la constructora un aplazamiento del comienzo de las obras hasta que no se dé una solución al problema de los 92 esqueletos que siguen diseminados por la superficie del solar (Levante-EMV, 28/3/96). Por su parte, el equipo arqueológico insiste en la necesidad de llevar a cabo el estudio antropológico. Mientras el Ayuntamiento negocia la cesión de una parte para su investigación, la Conselleria de Cultura de la Generalitat Valenciana, a través de la Direcció General de Patrimoni Artístic, anuncia su disposición a autorizar el traslado al cementerio judío de Madrid o Barcelona, indicando que, en buena lógica, deberían ser estudiados previamente (Levante-EMV, 29/ 3/96). Definitivamente, el 10 de abril, el Gran Rabinato de Jerusalén decide la reinhumación en el cementerio judío de Barcelona sin dejar opción al estudio de una parte, como se pretendía desde el Ayuntamiento. Éste, a través de su Concejalía de Cultura, manifiesta su conformidad con esta decisión (Levante-EMV, 12/4/96). El 17 de abril las máximas autoridades municipales y de la Conselle- ria de Cultura presiden la ceremonia de exhumación (Lám. I). Tras ella, el entonces Conseller de Cultura, Fernando Villalonga, en declaraciones a los medios de comunicación, reconoce que se había dado una situación que rebasaba el mero interés arqueológico, lo que había planteado un conflicto con la tradición religiosa hebrea cuyo respeto debía anteponerse al interés arqueológico (Levante-EMV, 17/4/96).

Ante el cariz que habían tomado los acontecimientos, diversos colectivos salieron a la palestra para manifestar su desacuerdo con la solución dada a este conflicto.Así, según la Comisión deArqueología del Colegio de Doctores y Licenciados en Filosofía, Letras y Ciencias deValencia y Castellón, la reinhumación impediría la revisión que cualquier estudio histórico exige con el tiempo y más aún, tratándose de técnicas de investigación en antropología y paleopatología forense que experimentan continuos avances (Levante-EMV, 13/4/96). En idénticos términos se expresó el Presidente de la Asociación Española de Paleopatología y catedrático de Medicina Legal de la Universidad de Valencia, Delfín Villalaín, para quien el traslado suponía una pérdida para la historia de Valencia (Levante$E M V, 18 / 4 / 96)$. Por su parte, el Departamento de Prehistoria y Arqueología de la Universidad de Valencia, difundió un comunicado en el que se recordaba que la excavación arqueológica de la que procedían los restos judíos, era una actividad contemplada en el marco jurídico del aconfesional Estado Español, concretamente, en la LPHE (16/ 85), complementada por los distintos reglamentos autonómicos que regulan las excavaciones arqueológicas (Orden de 1987 de la Generalitat Valencia$n a)$ (2). Igualmente, se recordaba que la LPHE (16/ 85) proclama el carácter público de todos los restos de interés histórico contenidos en el subsuelo y exige su estudio con metodología arqueológica. En este caso, la autoridad competente, local y autonómica, había incumplido el preceptivo acto de depósito del registro arqueológico recuperado completo, autorizando en cambio, el traslado de los restos humanos al cementerio judío de Barcelona, lo que había provocado la pérdida de una información de gran valor para profundizar en el conocimiento de la población judía bajomedieval de Valencia ( $L e$ vante-EMV, 20/4/96).

(2) Por estas fechas, aún no se disponía de la Ley de Patrimonio Cultural Valenciano, aprobada por las Cortes Valencianas en la sesión celebrada el 3 de junio de 1998. Corts Valencianes, Diari Oficial de la Generalitat Valenciana 249 de 24 de junio de 1998.

T. P., 58, n. $^{\circ} 2,2001$ 


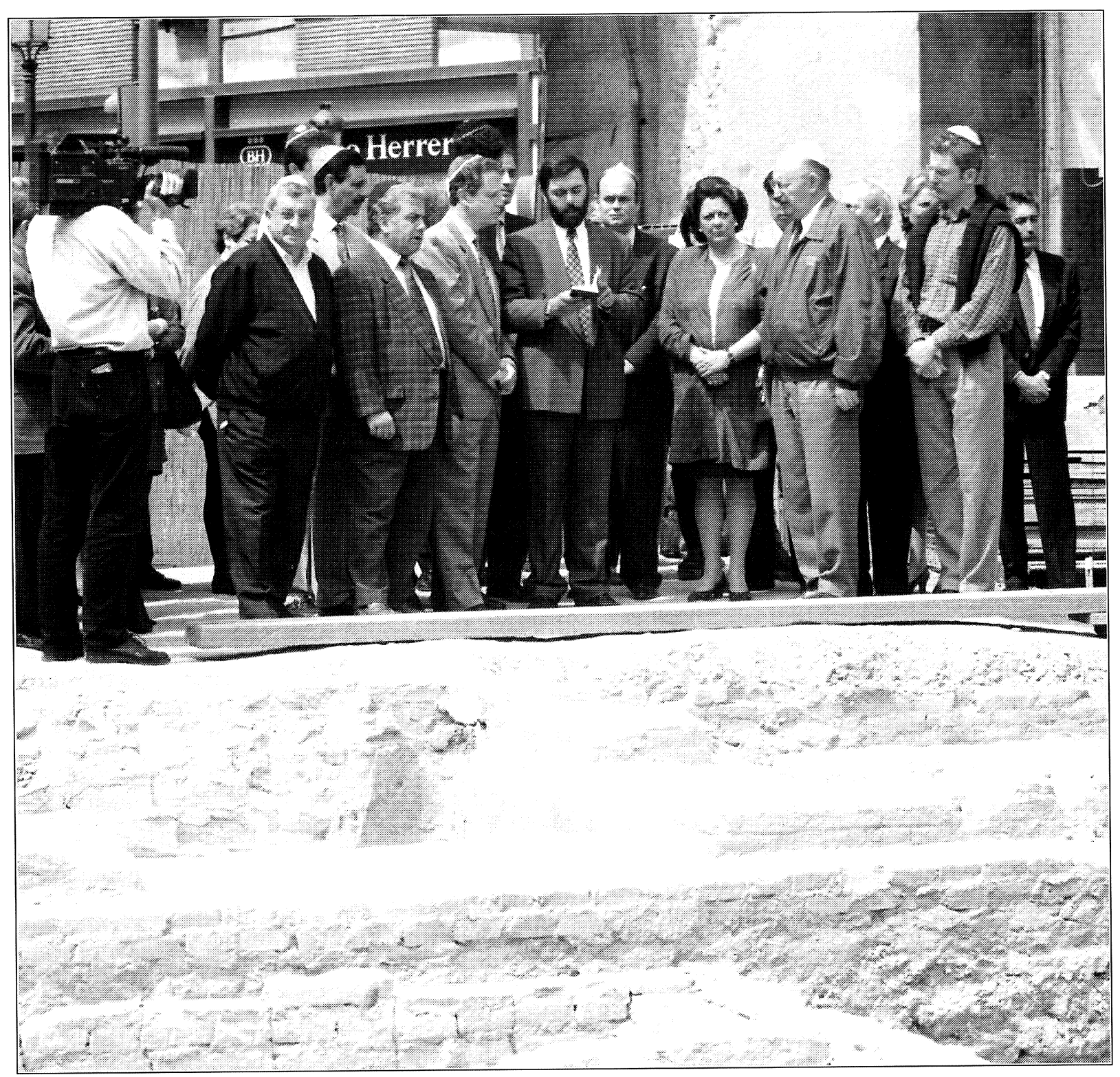

Lám. I. Ceremonia religiosa previa a la exhumación de los cadáveres de la c/ Dr. Romagosa, con la asistencia de la alcaldesa de Valencia y el entonces conseller de Cultura a la izquierda del rabino, el día 17 de Abril de 1996 (foto Ferrán Montenegro, Levante-EMV).

\section{LA IMPOSICIÓN DE UNA TRADICIÓN RELIGIOSA FRENTE A LA DEFENSA DEL PATRIMONIO HISTÓRICO}

La solución dada al conflicto de la necrópolis judía de Valencia implica la consideración de unos bienes arqueológicos, en este caso huesos humanos, como patrimonio exclusivo de una comunidad religiosa como es la judía. Ésta basó su postura tajante al amparo del cumplimiento estricto de sus leyes que establecen el carácter inviolable de los lugares de culto judío entre los que se incluyen los cementerios. Así se contempla en el Acuerdo de Cooperación del Estado Español con las Comunidades Israelitas de España de 10 de noviembre de 1992 (BOE 272 de 12 de noviembre) (Ley 24/1992), cuyo art. 2 , aptdo. 2 señala que: los lugares de culto en las comunidades pertenecientes a la Federación de Comunidades Israelitas gozan de inviolabilidad en los términos establecidos en las leyes; y añade el 
aptdo. 6 del mismo art.: los cementerios judios gozarán de los beneficios legales que este art. establece para los lugares de culto, así como se reconoce el derecho a trasladar a los cementerios pertenecientes a las comunidades israelitas los cuerpos de los difuntos judios, tanto de los actuales inhumados en cementerios municipales como de aquellos cuyo fallecimiento se produzca en localidad en la que no exista cementerio judío.

$\mathrm{Al}$ amparo de esta normativa legal, la Comunidad Judía se sintió legitimada para exigir el cese de la excavación arqueológica y prohibir cualquier tipo de análisis científico de los mismos, así como autorizar su exhumación para trasladarlos a algún cementerio perteneciente a las comunidades israelitas. Sin embargo, el mismo art. 2 en su aptdo. 1 señala que a todos los efectos legales son lugares de culto de las comunidades pertenecientes a la Federación de Comunidades Israelitas de España los edificios o locales que estén destinados de forma permanente y exclusiva a las funciones de culto. Resulta evidente que de acuerdo con este texto el espacio donde se ubicaba el "Fossar dels Juheus" no puede ser considerado como lugar de culto, ya que no había conservado dicha función (Figs. 1 y 2); en realidad, debe ser contemplado como una zona arqueológica, quedando protegida como tal por la LPHE (16/85). Esta misma ley proclama el carácter público de todos los restos de interés histórico contenidos en el subsuelo y exige su estudio con metodología arqueológica. En consecuencia, la Comunidad Judía no podía arrogarse un derecho hasta el punto de impedir una investigación ajustada a la normativa legal y contemplada, además, en la Ley 24/1992, que en su art. 13 señala que: el Estado y la Federación de Comunidades Israelitas colaborarán en la conservación y fomento del patrimonio histórico, artístico y cultural judio, que continuará al servicio de la sociedad para su contemplación y estudio. De hecho, no faltan ejemplos en los que ha sido posible hacer compatibles los principios religiosos y científicos, como se demostró en el cementerio judío deYork (Inglaterra) (Lilley et alii, 1994), donde tras el estudio, los restos se reinhumaron cumpliendo con los ritos judíos.Y lo mismo puede decirse de la necrópolis judía de Zaragoza (Motis, 1991: 67-83), o la excavación de la necrópolis de la aljama judía de Sevilla, acometida en 1992 con toda normalidad y en la que se incluyó el estudio paleoantropológico durante el desarrollo de la excavación que pudo analizar 73 cadáveres fechados entre mediados del siglo XIII y el último cuarto del siglo XV (Santana, 1995: 2325, 81-108; 1996). Recientemente, se daba noticia de la excavación de doscientas tumbas de los siglos XI y XII en el cementerio judío de Girona (Levante-EMV, 6/4/00).

Teniendo en cuenta todos estos precedentes, alguno de ellos tan reciente como el de la necrópolis judía de Sevilla, resulta más incomprensible la actitud de las instituciones políticas valencianas de plegarse ante las exigencias de la Comunidad Judía, incumpliendo el marco legal, al no proceder como contempla la LPHE (16/85) en materia de excavaciones arqueológicas y quedar obviado todo el procedimiento administrativo habitualmente exigido al resto de intervenciones arqueológicas en favor de un oscurantismo acientífico y sectario innecesario, así como discriminatorio con otras confesiones. Pero no sólo se ha conculcado la LPHE (16/85), sino que lo mismo puede decirse de la Ley 24/1992. El Estado; en lugar de colaborar con las comunidades israelitas en la conservación y fomento del patrimonio histórico, artístico y cultural judío, se ha plegado a los intereses privativos de una organización religiosa. Esta actitud va en contra de la Constitución Española de 1978, cuyo art. 16.3 sanciona el carácter laico del Estado español y lo mismo cabe decir del art. 46 cuando señala que los poderes públicos garantizarán la conservación y promoverán el enriquecimiento del Patrimonio histórico, cultural y artístico de los pueblos de España y de los bienes que lo integran, cualquiera que sea su régimen jurídico y su titularidad. La ley penal sancionará los atentados contra este patrimonio. La actuación de los poderes públicos en este asunto, obviamente no ha garantizado la conservación ni ha promovido el enriquecimiento del Patrimonio histórico, artístico y cultural español, sin perjuicio de que además, la titularidad de los bienes hallados en ningún caso pertenezca a la Comunidad Judía.

Como viene sucediendo desde hace años, de manera especial con los aborígenes australianos o de los EE. UU. (Endere, 2000: 4-5), las administraciones deben procurar conciliar los aspectos científicos legales con las sensibilidades de los diferentes sectores socioculturales. En el caso que nos ocupa, ni tan siquiera se permitió el estudio paleoantropológico, como se lleva habitualmente a cabo en el caso de esqueletos prehistóricos, romanos o musulmanes; la ley y la lógica científica así lo aconsejaban con independencia de que, a posteriori, se pudiese arbitrar una solución ecuánime para los restos.

T. P., 58, n. ${ }^{\circ} 2,2001$ 


\section{LA ACCIÓN DEL SÍNDIC DE GREUGES DE LA COMUNIDAD VALENCIANA Y SU RESOLUCIÓN CONDENATORIA DE LA ADMINISTRACIÓN}

A raíz de la decisión de trasladar los esqueletos sin su estudio previo y de los intentos de justificación por parte de las administraciones local y autonómica, un grupo de ciudadanos/as elevó una reclamación al Síndic de Greuges (Síndico deAgravios), tramitada desde el Departamento de Prehistoria y Arqueología de la Universidad de Valencia. ElSíndic de Greuges es una institución recogida por el Estatuto de Autonomía de la Comunidad Valenciana, similar al Defensor del Pueblo, contemplado en la Constitución Española. Como la de éste, su misión es velar por una correcta actuación de la administración en el ámbito territorial autonómico $(\mathrm{Ge}$ neralitat Valenciana, diputaciones provinciales y corporaciones locales), en relación con los derechos y libertades fundamentales de los ciudadanos/as. La reclamación fue admitida a trámite con el número 960794, en carta remitida a la primera firmante el 1 de julio de 1996. Dada la ausencia de regulación para un conflicto de estas características, la resolución del Síndic de Greuges posee el valor especial de todo aquello que sienta un precedente; de ahí que hayamos considerado oportuna la inclusión literal de una buena parte de su contenido (3) .

En el escrito de reclamación presentado al entonces Síndic de Greuges, Arturo Lizón Giner, se consideraba que tanto la Conselleria de Cultura, Educació $i$ Ciència de la Generalitat Valenciana, como elAyuntamiento deValencia estaban conculcando los arts. 44 (acceso a la cultura y promoción de la investigación) y 46 (conservación del patrimonio histórico) de la Constitución Española y, en consecuencia, incumpliendo sus leyes reguladoras, como la LPHE (16/85) y la Orden autonómica sobre actividades arqueológicas del 31 de julio de 1987 (4).

La LPHE (16/85) proclama el carácter público de todos los restos de interés histórico contenidos en el subsuelo y exige su estudio con método arqueológico. Además, en el reglamento autonómico citado se recoge que los hallazgos procedentes de excavaciones regladas se depositen en el museo designado y se presente un informe preliminar, así

\footnotetext{
${ }^{3}$ El texto de la resolución fue redactado en valenciano. Para esta ocasión nos ha parecido oportuno traducir al castellano las partes que se han incluido del texto original.

${ }^{4}$ Vide nota 3 .
}

como una memoria científica definitiva en los plazos designados (arts. 15, 16 y 17).

La oficina del Síndic de Greuges solicitó a las instituciones implicadas que emitieran sendos informes sobre la decisión tomada. LaDirecció General de Patrimoni Artístic de la Conselleria de Cultura, Educació i Ciència basó el suyo en el respeto a las costumbres funerarias judías, amparándose en la Ley 24/1992 y en la ausencia de una regulación para conflictos similares. Hemos considerado oportuno reproducir la parte fundamental de este informe:

Quinto.-El carácter reciente de la ley aprobatoria (sic) los Acuerdos de Cooperación, en relación con la LPHE 16/85 y la Orden del 31 de julio de 1987, reguladora de la concesión de autorizaciones para las excavaciones arqueológicas, provoca el que no exista previsión específica reguladora de estos conflictos de derechos. Por ello, la actuación de la Conselleria y de esta Dirección General en particular, ha sido la de mediar en el conflicto, por una parte, realizando los esfuerzos necesarios para proteger al menos la integridad de los restos (enviando una comunicación de 9 de abril al Ayuntamiento de Valencia, indicando la no procedencia de cualquier obra que pudiera afectar a la misma) y de intentar obtener el consentimiento de la comunidad judía para que permitiera el estudio de los mismos (hay que señalar que con anterioridad a la oposición de la Comunidad judía, restos procedentes de excavaciones anteriores fueron objeto de investigación arqueológica), como lo manifiesta el oficio de 8 de febrero de 1996, remitido por el Servicio de PatrimonioArqueológico a las Comunidades, que indica la posibilidad de autorizar el traslado de los restos previo estudio arqueológico.

Los intentos de mediar en el conflicto chocan con la actitud intransigente de las comunidades israelitas:

Sin embargo, las comunidades israelitas, acogiéndose a la inviolabilidad de los restos y a que sus creencias religiosas impedían su manipulación científica, amparándose en su derecho a que se respetaran las reglas tradicionales judias, no permitieron que continuara el estudio de los restos.

Sexto.-La Orden Reguladora de concesión de permisos para la realización de excavaciones arqueológicas, establece la posibilidad de que la administración autorice el traslado fuera de la Comunidad Valenciana de los restos arqueológicos procedentes de la misma.

La Comunidad Israelita solicitó formalmente a 
la Conselleria de Cultura el traslado de los restos humanos al Cementerio Judio de Barcelona en fecha 11 de abril. ElConseller de Cultura, Educación y Ciencia, valorando las circunstancias concretas del caso y la normativa legal, decidió autorizar el traslado de los mismos a dicho cementerio.

En última instancia, la Conselleria de Cultura actúa condicionada por el temor a provocar un conflicto:

La voluntad de esta Conselleria ha sido, en última instancia, y dentro del marco legal en que se movía la cuestión, la de evitar cualquier conflicto que pudiera haber reabierto las viejas heridas producidas a la Comunidad Judía en España, asegurando en todo caso la integridad de los restos, sin perjuicio de que en un futuro, en la mencionada Comisión de Seguimiento de los Acuerdos entre la Administración del Estado y la Federación de Comunidades Israelitas se puedan ofrecer criterios consensuados que armonicen más adecuadamente el derecho a la libertad religiosa y el de investigación científica para casos similares.

ElAyuntamiento de Valencia, a través del Servicio de Patrimonio Histórico y Cultural, remitió los antecedentes correspondientes al expediente tramitado y adjuntó un informe en que documentaba las diferentes actuaciones arqueológicas hasta el acuerdo de la Comisión de Gobierno de 12 de abril de 1996 que autorizó el traslado y la reinhumación de los restos humanos encontrados en la excavación al cementerio judío de Barcelona, y hacía extensiva la autorización a los procedentes de intervenciones anteriores y que se encontraban en dependencias municipales. En idénticos términos se pronunció la Conselleria de Cultura en resolución de la misma fecha, y el tema quedó, desde ese momento, fuera de la competencia de los servicios municipales en materia arqueológica.

Trasladados estos informes a los promotores de la queja, éstos presentaron un escrito de alegaciones nuevamente, tramitado desde el Departamento de Prehistoria yArqueología de la Universidad deValencia, del que reproducimos su parte fundamental:

- Los restos antropológicos son, más allá de su consideración como restos humanos, objeto de protección y estudio por su consideración como bienes de interés colectivo.

- El estudio científico de los restos no entra en conflicto con el derecho a la libertad religiosa.

- El art. 13 delAcuerdo de Cooperación (...) señala que su finalidad es colaborar en la conservación del Patrimonio de forma que pueda continuar al servicio de la sociedad para su contemplación y estudio, aspectos que no han sido respetados de ninguna manera.

- Ante el conflicto existente entre dos normas jurídicas (LPHE 16/85 yAcuerdo de Cooperación), se considera que habría que primar la primera.

- Debería mantenerse una actitud dialogante que permitiera alcanzar un acuerdo que conciliase los intereses de ambas partes, cubriendo el vacío existente a nivel normativo. Lo que en todo caso se considera inadecuado es la cesión incondicionada que ha realizado la Conselleria de Cultura a las exigencias religiosas, que deja completamente al margen los intereses científicos y culturales de la colectividad.

La resolución final del Síndic de Greuges fue dictada con fecha 28 de febrero de 1998, es decir, prácticamente dos años después de los acontecimientos que dieron lugar a esta queja. Los fundamentos de derecho de la citada resolución se basan en saber si se ha respetado el adecuado equilibrio entre dos derechos constitucionales, el derecho a la cultura (art. 44) y su preservación (art. 46), recordados por los promotores de la queja y el de libertad religiosa (art. 16), sobre el que las administraciones afectadas fundaron su actuación.

En lo que respecta al art. 16 de la Constitución Española, el Síndic de Greuges alude a sendas sentencias del Tribunal Constitucional (sentencias 24/ 1982 y 166/1996) que declaran que la libertad religiosa, entendida como un derecho subjetivo de carácter fundamental, se concreta en el reconocimiento de un ámbito de libertad y de una esfera de agere licere del individuo, es decir, reconoce el derecho de los ciudadanos a actuar en este campo con plena inmunidad de coacción del estado y de cualquier grupo social.

Desde otra perspectiva el art. 16.3 de la Constitución proclama que ninguna confesión tendrá carácter estatal e impide por tanto, como dicen los recurrentes, que los valores o intereses religiosos se erijan en parámetros para medir la legitimidad o justicia de las normas y de los actos de los poderes públicos. Al mismo tiempo, el citado precepto constitucional veda cualquier tipo de confusión entre funciones religiosas y funciones estatales (Sentencia 24/82).

Finalmente, el alto tribunal ha tenido oportunidad de pronunciarse en diversas ocasiones en relación a situaciones de conflicto entre la libertad religiosa e ideológica y otros derechos fundamentales y señala que sólo ante los límites que la mis-

T. P., 58, n. ${ }^{\circ} 2,2001$ 
ma Constitución expresamente impone al definir cada derecho o ante los que de manera mediata $o$ indirecta se infieran de ésta al resultar justificados por la necesidad de preservar otros derechos constitucionales protegidos, pueden ceder los derechos fundamentales (...) y por otra que, en todo caso, las limitaciones que se establezcan no pueden obstruir el derecho más allá de lo razonable, (...) de manera que los actos o las resoluciones que limiten derechos fundamentales han de asegurar que las medidas limitadoras sean necesarias para conseguir el fin perseguido (...) y han de atender la proporcionalidad entre el sacrificio del derecho y la situación en que se encuentra aquel a quien se le imponga (...) y, en todo caso, respetar su contenido esencial (...) si tal derecho todavía puede ejercerse (Sentencia 120/90).

En consecuencia, el derecho a la libertad religiosa implica:

- Ámbito de libertad, con plena inmunidad de coacción del estado y de los grupos sociales.

- Principio de igualdad, de manera que las actitudes religiosas no pueden implicar diferencias de trato jurídico.

- Separación estado-confesiones religiosas, de manera que los valores o intereses religiosos no pueden ser parámetros válidos para mesurar la legitimidad de las normas y de los actos de los poderes públicos.

- De forma análoga a la situación en que se encuentran el conjunto de derechos y libertades, no posee un alcance ilimitado, sino que en caso de conflicto con otros derechos, ha de buscarse el oportuno equilibrio entre ello, incluso pueden ceder si resulta justificado por la necesidad de preservar otros derechos constitucionalmente protegidos.

En relación con los arts. 44 y 46 de la Constitución Española, el Síndic señala:

El precepto constitucional cuya vulneración fundamenta la presentación de la presente queja es el proclamado en el art. 46, que establece el mandato positivo dirigido a todos los poderes públicos de conservar y promover el enriquecimiento del Patrimonio Histórico, Cultural yArtístico de los pueblos de España. (...) La citada prescripción cobra una particular relevancia constitucional, como integrante del derecho a la cultura proclamado en su art. 44.

Cabe recordar que el preámbulo de nuestra norma suprema proclama la voluntad de la nación española de promover el progreso de la cultura, como también de proteger a todos los españoles y pueblos de España en el ejercicio de los derechos humanos, sus culturas y tradiciones, lenguas e instituciones.

Por tanto, el mismo preámbulo constitucional como declaración de voluntad del constituyente y síntesis del contenido esencial de sus preceptos, proclama señaladamente el derecho a la cultura como mecanismo para conseguir el establecimiento de la justicia, la libertad y la seguridad. (...) En definitiva, el art. 46 se convierte en una manifestación en el ámbito cultural de los principios contenidos en el art. 9.2 de la Constitución, de acuerdo con el que corresponde a los poderes públicos promover las condiciones para que la libertad y la igualdad del individuo y de los grupos en que se integran sean reales y efectivo; superar los obstáculos que impidan o dificulten su plenitud y facilitar la participación de todos los ciudadanos en la vida política, económica, cultural y social.

Los principios recogidos en los arts. 44 y 46 de la Constitución Española se desarrollan en la exposición de motivos de la LPHE (16/85):

(...) el Patrimonio Histórico Español es una riqueza colectiva que contiene las expresiones más dignas de estimación en la aportación histórica de los españoles a la cultura universal. Su valor lo proporciona la estima que, como elemento de identidad cultural, merece la sensibilidad de los ciudadanos. (...) Porque en un estado democrático estos bienes han de estar adecuadamente puestos al servicio de la colectividad en el convencimiento de que con su disfrute se facilita el acceso a la cultura y que ésta, en definitiva, es camino seguro hacia la libertad de los pueblos.

En términos legales, las administraciones implicadas consideraron que había un conflicto entre los preceptos constitucionales y la Ley 24/192:

Dentro de la (segunda) hay dos preceptos fundamentales a considerar:

- El art. 2.6 que establece que los cementerios judios gozarán de los beneficios legales que el mismo art. establece para los lugares de culto, y se fijan una serie de derechos como ahora el de poseer cementerios privados, disponer de parcelas reservadas en los cementerios municipales, trasladar a sus cementerios propios sus difuntos y la observación de las reglas tradicionales judías para inhumaciones, sepulturas y ritos funerarios.

- El art. 13 dispone que "el estado y la Federación de Comunidades Israelitas de España colaborarán en la conservación y el fomento del Patrimo- 
nio Histórico, Artístico y Cultural judío, que continuará al servicio de la sociedad para su contemplación y estudio".

Por su parte, la Ley del Patrimonio Histórico Español define como un integrante de tal patrimonio los inmuebles y objetos muebles de interés arqueológico, y establece como objetivos a cumplir su protección, acrecentamiento y transmisión a las generaciones futuras (art. 1).

En este sentido la ley fija como un mandato positivo dirigido a las administraciones públicas competentes la adopción de las medidas necesarias para garantizar su conservación, promover su enriquecimiento y fomentar y tutelar el acceso a todos los ciudadanos (art. 2).

En concreto y como parte de aquel, el Patrimonio Arqueológico queda integrado, según dispone el art. 40 "por los bienes muebles e inmuebles de carácter histórico susceptibles de ser estudiados con metodología arqueológica, hayan sido o no extraídos y tanto si se encuentran en la superficie o en el subsuelo, en el mar territorial o en la plataforma continental". Este conjunto de bienes se considerará de dominio público, en aplicación del art. 44 de la ley.

Una vez establecidos los términos constitucionales y legales de la controversia, el Síndic de Greuges muestra su total discrepancia con las medidas adoptadas por las administraciones implicadas, al considerar que sólo se tuvo en cuenta la libertad religiosa con total sacrificio del derecho a la cultura de los ciudadanos:

No podemos compartir la afirmación que se contiene en los informes emitidos, que postulan una derogación de los preceptos contenidos en la Ley del Patrimonio Hisíórico Español en lo concerniente, única y exclusivamente, a los cementerios judíos, en virtud del art. 2 de la Ley 25/1992 en aplicación de los principios que donde la ley no distingue el intérprete no ha de distinguir, y que la ley posterior deroga la anterior.

En primer lugar, habría que efectuar una aplicación integra de los preceptos de la Ley 25/1992 y por eso su art. 2 ha de interpretarse en relación con el art. 13, anteriormente citado, que prescribe la colaboración estado-Federación de Comunidades Israelitas de España para la conservación y el fomento del Patrimonio Cultural, y el compromiso en todo caso, de ponerlo al servicio de la sociedad para su estudio.

La justificación legal de esta resolución condenatoria se basa en que el llamado Fossar dels Jueus había dejado de funcionar como cementerio durante la primera mitad del siglo XV, edificándose sobre el mismo una parte de la ciudad (Fig. 2, 1 y 2). En consecuencia, debe entenderse que la normativa estatal que regula y protege los cementerios no puede aplicarse a un área que se convirtió en urbana.Además, dado que los cementerios antiguos carecen de una normativa específica deben considerarse como parte integrante del Patrimonio Histórico Español:

Desde otra perspectiva, en cuanto al término "cementerio", si bien en el lenguaje común abarca el espacio de terreno destinado al entierro de cadáveres, entendemos que en el derecho positivo español debe efectuarse una distinción entre lo que suponga una instalación destinada actualmente a tal fin y que mantenga su funcionalidad, y lo que suponga un cementerio que finalizó su función en la primera mitad del siglo XV, sobre el que se edificó parte de la ciudad de Valencia y que ha sido descubierto con motivo de excavaciones arqueológicas.

De esta manera, el ámbito de aplicación de la normativa dictada por el estado para regular los cementerios, a pesar de no venir definida expresamente, está constituido por los que conservan su función como tales, centrándose en sus aspectos técnicosanitarios (Reglamento de Policía Sanitaria Mortuoria, aprobado por Decreto 2263/74) o los aspectos ideológicos y religiosos que hay que considerar y respetar en los entierros (Ley 49/78 de Entierros en Cementerios Municipales). Es en este ámbito en el que entendemos que debe incluirse el art. 2 de la Ley 25/1992.

Los cementerios antiguos que perdieron su funcionalidad por el paso del tiempo y la acción humana y que se conozca su existencia, así como sus restos, por intervenciones arqueológicas, carecen de una normativa que especificamente los recoja, teniendo en cuenta que han de considerarse integrados en el concepto de Patrimonio Arqueológico, como elemento integrante del Patrimonio Histórico Español y, por tanto, sometidos a la Ley 16/ 1985. En este ámbito habría que considerar incluido el art. 13 de la Ley 25/1992.

Por tanto, a juicio de esta institución no hay derogación alguna de los preceptos contenidos en la Ley del Patrimonio Histórico Español en este punto, sino que es necesario efectuar una interpretación integrada y armónica de los diversos preceptos en juego, considerando que, por aplicación del art. 13 de la ley aprobatoria del Acuerdo entre el Estado y Federación de Comunidades Israelitas de España, la presencia de restos arqueológicos de un

T. P., 58, n. ${ }^{\circ} 2,2001$ 

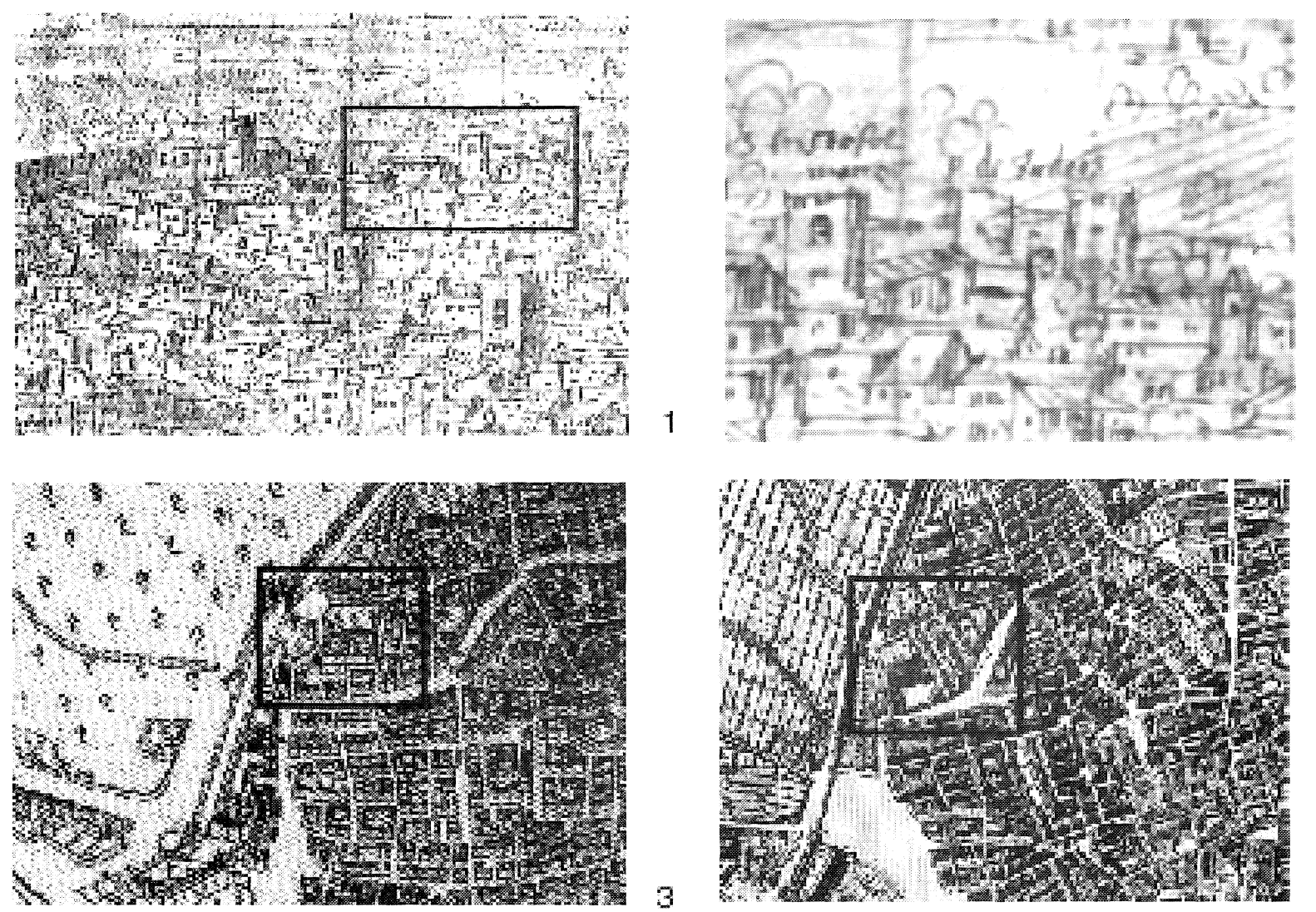

Fig. 2. Vistas parciales de la ciudad deValencia donde se puede ver el emplazamiento del cementerio judío totalmente construido: 1, Dibujo de Anthonie van den Wijngaerde (1563); 2, Detalle de la puerta de los judíos del mismo autor; 3, Grabado de 1608; 4, Grabado del padre Vicent Tosca (1703).

antiguo cementerio, requieren la aplicación de las previsiones establecidas en las normas nacionales referidas al Patrimonio Arqueológico.

Por otro lado, el Síndic de Greuges cita elAcuerdo entre el Estado Español y la Santa Sede sobre enseñanza y asuntos culturales de 3 de enero de 1979 como ejemplo legal para evitar conflictos entre la libertad religiosa y el derecho a la cultura, buscando fórmulas de equilibrio que, sin menoscabo ni ofensa de los fines religiosos, mantenga los bienes culturales dentro del Patrimonio Histórico de la colectividad:

El hecho de que buena parte del Patrimonio (Histórico) esté en manos de entidades religiosas y, singularmente en nuestro país la iglesia católica sea titular de la inmensa mayoría de los bienes integrantes, ha determinado la existencia de una completa regulación que resuelva las posibles situaciones de conflicto.

De esta manera en el Acuerdo entre el Estado Español y la Santa Sede sobre enseñanza y asuntos culturales de 3 de enero de 1979 en los arts. XV y $X V I$ recogía el contenido de lo concordado en relación con los bienes histórico-artísticos propiedad de la iglesia, y en el primero señala que "la iglesia reitera su voluntad de continuar poniendo al servicio de la sociedad su patrimonio histórico, artístico y documental, y concertará con el estado las bases para hacer efectivos el interés común y la colaboración de ambas partes con el fin de preservar, dar a conocer y catalogar este patrimonio cultural en posesión de la iglesia, de facilitar su contemplación y estudio, de conseguir la mejor conservación y de impedir cualquier clase de pérdida, en el marco del art. 46 de la Constitución".

En el documento aprobado, en el apartado primero, el estado "reafirma su respeto a los derechos que tienen las personas jurídicas eclesiásticas sobre estos bienes, de acuerdo con los títulos jurídicos correspondientes», y la iglesia por su parte "reconoce la importancia de este patrimonio, no sólo para la vida religiosa, sino para la historia y la cultura 
española, y la necesidad de conseguir una actuación conjunta con el estado para su mejor conocimiento, conservación y protección".

Finalmente, el aptdo. tercero establece los principios a que ha de atenerse la cooperación en el tratamiento de estos bienes, entre los cuales hay los siguientes:

“a) El respeto del uso preferente de estos bienes en los actos litúrgicos y religiosos y su utilización, de acuerdo con su naturaleza y finalidades, por sus legítimos titulares.

b) La coordinación de este uso con el estudio científico y artístico de los bienes y su conservación.

d) Las normas de la legislación civil de protección del Patrimonio Histórico-artístico y Documental son de aplicación a todos los bienes que merecen tal calificación, cualquiera que sea su titular".

Consideramos que los principios reseñados, sin perjuicio de no ser directamente aplicables a las comunidades israelitas de España, constituyen una manifestación clara y terminante de la relación existente entre la libertad religiosa y el derecho a la cultura (...) Se establece como premisa fundamental la sujeción de estos bienes a la legislación sobre Patrimonio Histórico artístico y se postula en todo caso su estudio con métodos científicos.

Sin perjuicio de ello se respeta la vinculación y el destino al culto o a fines religiosos, y se busca una fórmula de equilibrio que, sin menoscabo ni ofensa de los fines religiosos mantenga los bienes dentro del Patrimonio Histórico de la colectividad.

En consecuencia, se debería haber aplicado un equilibrio entre los dos derechos fundamentales permitiendo el estudio de los restos encontrados. Pero dado el carácter sagrado que se atribuye a los enterramientos, se podría permitir la participación de representantes de las autoridades religiosas en el proceso de investigación y, después de estudiados, determinar el destino final de los mismos:

Esta es la vía que esta institución considera que habría de utilizarse en casos como el que nos ocupa. Habría que partir de la ineludible necesidad que los restos del cementerio encontrados se estudiasen con métodos arqueológicos para permitir la obtención de los conocimientos científicos que puedan extraerse, para la mejor comprensión de nuestra historia.

Sin perjuicio de ello, la consideración de que nos encontramos ante restos humanos, con el valor sagrado que se atribuye a los enterramientos, podría ser considerado a efectos de determinar el destino final de los restos una vez estudiados, y podría posibilitar la participación de representantes de las autoridades religiosas en el proceso de investigación para garantizar el respeto a causa de la sensibilidad religiosa, en el marco de las necesidades científicas e históricas, sin que en ningún caso se planteen mutuas exclusiones entre ambas.

Con objeto de evitar la reproducción de situaciones como la (...) presente, (...), habrían de arbitrarse fórmulas de cooperación, y establecerse mecanismos que permitieran concretar y determinar sus disposiciones, a través de las comisiones que fueran necesarias para establecer el marco jurídico concreto de actuación en la materia.

La resolución concluye con una serie de recomendaciones dirigidas a las administraciones afectadas en este asunto:

En virtud de lo anteriormente expuesto, y en aplicación de lo que dispone el art. 29 de la Ley 11/ 1988, de 26 de diciembre, de la Generalitat Valenciana, del Síndic de Greuges, concluimos realizando las siguientes

A) Recomendación a la Direcció General de Patrimoni Artístic de la Conselleria de Cultura, Educació i Ciència y a laAlcaldía del Ayuntamiento de Valencia.

Convendrá desplegarse, en todo caso, la adecuada actividad administrativa que garantice la integración en el Patrimonio Histórico Español de todos los bienes muebles e inmuebles obtenidos por métodos arqueológicos, incluyendo los correspondientes a antiguos cementerios, con independencia de cualquier consideración de índole religiosa y que nunca pueda rebasar los límites establecidos en el conjunto de nuestro ordenamiento jurídico.

En consecuencia, deberán adoptarse las medidas necesarias para garantizar su integridad, conservación y su estudio desde el punto de vista científico, a fin de posibilitar la puesta a disposición de la sociedad de los conocimientos que puedan obtenerse sobre nuestra historia, evitando la pérdida de cualquier elemento integrante de nuestro patrimonio cultural.

B) Recomendación a la Direcció General de Patrimoni Artístic de la Conselleria de Cultura, Educació i Ciència.

Se recomienda el establecimiento de mecanismos de cooperación que permitan la adopción de acuerdos complementarios, a fin de establecer los

T. P., 58, n. $^{\circ} 2,2001$ 
principios y criterios conforme según los cuales han de resolverse las controversias que puedan surgir en las relaciones poderes públicos-confesiones religiosas en la defensa y conservación de los bienes integrantes del Patrimonio Histórico, buscando fórmulas de equilibrio que, con respeto a la significación religiosa de los bienes de que se trate, permitan preservar la íntegra aplicación de la legislación civil en la materia.

\section{CONCLUSIONES}

La resolución del Síndic de Greuges de la ComunidadValenciana sobre la queja presentada por un grupo de ciudadanos/as, motivada por la actuación de la Generalitat Valenciana y Ayuntamiento deValencia en relación con los enterramientos de la excavación arqueológica del cementerio judío de Valencia, ha sentado un precedente que puede marcar el rumbo de situaciones como la aquí analizada en las que se plantean conflictos de intereses entre creencias religiosas y acceso a la cultura (Endere, 2000: 6). De hecho, tanto la Conselleria de Cultura, como el Ayuntamiento de Valencia han reaccionado de manera positiva, al manifestar su disposición a aceptar la recomendación del Síndic de Greuges (Levante-EMV, 15/9/98).

En este caso, el respeto a una creencia religiosa prevaleció a costa del total sacrificio del derecho a la cultura de los ciudadanos. Con la decisión de autorizar el traslado de restos humanos de diversas excavaciones, se provocó la pérdida de un retazo de la historia de esta ciudad, sustrayendo del estudio científico una parte de su patrimonio arqueológico. Lo más grave es que esta decisión provino de las administraciones encargadas de gestionar el patrimonio cultural de la ciudad de Valencia, contraviniéndose el marco legal vigente en materia de patrimonio histórico:

- En primer lugar, el art. 46 de la Constitución Española, desde el momento en que son los poderes públicos los que garantizarán la conservación y promoverán el enriquecimiento del patrimonio histórico, cultural y artístico de los pueblos de España y de los bienes que lo integran, cualquiera que sea su régimen jurídico y su titularidad.

- En segundo lugar, la LPHE (16/85) de 25 de junio, desde el momento en que los cementerios antiguos al carecer de normativa específica deben considerarse como parte integrante de dicho Patrimonio. Esta ley proclama el carácter público de todos los restos de interés histórico contenidos en el subsuelo, como es este caso, y exige su estudio con método arqueológico (art. 44).

- En tercer lugar, la Ley 24/1992, que contempla la colaboración de ambas partes para la conservación y fomento del patrimonio histórico, artístico y cultural judío que continuará al servicio de la sociedad para su contemplación y estudio (art. 13).

Las administraciones autonómica y local de Valencia justificaron su decisión en la ausencia de una normativa específica reguladora de este tipo de conflictos de intereses. En otras confesiones sí que hay ejemplos legales que pueden utilizarse como marco de referencia. Es el caso del Acuerdo entre el Estado Español y la Santa Sede sobre enseñanza y asuntos culturales de 3 de enero de 1979, suscrito entre otras razones para evitar conflictos entre la libertad religiosa y el derecho a la cultura, y que contempla fórmulas de equilibrio que, sin menoscabo ni ofensa de los fines religiosos, mantengan los bienes culturales dentro del patrimonio histórico de la colectividad. En la excavación arqueológica del cementerio judío medieval de Valencia podía haberse buscado una fórmula de este tipo en la que como premisa fundamental los bienes arqueológicos, en este caso huesos humanos, hubiesen quedado sujetos a la legislación sobre patrimonio histórico y por ello, objeto de estudio con metodología arqueológica, aunque su valor sagrado debería ser tenido en cuenta a efectos de determinar el destino final de los mismos una vez estudiados.

Desde el punto de vista de la gestión del patrimonio arqueológico (Querol y Martínez, 1996: 25-30), es evidente que por parte de las administraciones local y autonómica, no se han dado las condiciones para hacer efectivo el conocimiento, conservación y difusión de los enterramientos de la necrópolis judía de Valencia. A este respecto, hay que recordar que la LPHE (16/85) entiende por expolio toda acción u omisión que ponga en peligro de pérdida o destrucción todos o algunos de los valores de los bienes que integran el Patrimonio Histórico Español o perturben el cumplimiento de su función social. A la vista de los hechos aquí analizados, la solución dada a los restos humanos de la excavación del cementerio judío de Valencia constituyó un verdadero caso de expolio, provocado por las administraciones encargadas de velar por la integridad del patrimonio cultural valenciano. 


\section{AGRADECIMIENTOS}

A los directores de las diversas campañas de excavación en la necrópolis judía de Valencia, Matías Calvo y Vicent Lerma (1993 y 1995), Matías Calvo y Josep Burriel (1996) por la información facilitada; a Matías Calvo también por la posibilidad de citar su tesis de licenciatura inédita; aAlbert Ribera y Vicent Lerma por sus valiosos puntos de vista sobre esta intervención arqueológica; a Ángel Ventura por facilitarnos la bibliografía sobre la necrópolis judía de Sevilla; a Agustín Díez Castillo por la traducción al inglés del resumen.

\section{BIBLIOGRAFÍA}

Calvo, M. y Lerma, J.V. (1996): "El Fossar dels Juheus". Saitabi, 46: 261-275.

- (1998): "Peste negra y pogrom en la ciudad de Valencia. La evidencia arqueológica". Revista de Arqueología, 206: 50-59.

Endere, Ma.L. (2000): "Patrimonios en disputa: acervos nacionales, investigación arqueológica y reclamos étnicos sobre restos humanos". Trabajos de Prehistoria, 57, 1: 1-13.

Hinojosa, J. (1999): Los judíos en tierras valencianas. Diputació de València, Valencia.

LaCaVe, J.L. (1987): Sefarad, Sefarad: La España judía. Ed. Lunwerg, Barcelona.

- (1991): "Judíos en España". En E. Romero (dir.): La vida judía en Sefarad. Ministerio de Cultura. Madrid: 17-42.

Lilley, J.M.; Stroud, J.; Brothwell, D.R. y Williamson, M.H. (1994): The Jewish Burial Ground at Jewbury. York Archaeological Trust. York.
Motis, M.A. (1991): "El cementerio judío de Zaragoza". Cuadernos de Zaragoza, 63: 67-83.

Pérez Herrero, E. (1978): “Apuntes para el estudio de las necrópolis judías de época medieval o ensayo de tipología sepulcral". Sefarad, XXXVIII, 2: 333-355.

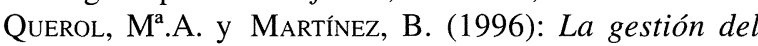
patrimonio arqueológico en España. Alianza, Madrid.

Ribera, A. (1989): “Arqueología urbana como marco de una profesión. Metodología y aplicación en el Servicio de Investigaciones Arqueológicas del Ayuntamiento de Valencia". Curso de Arqueología Urbana. Zarautz: 2128.

- (1995): "L'arqueologia a la ciutat de València: del nores (1981) a la més absoluta misèria (1994)".Actes de les Jornades d'Arqueología (Alfàs del Pi, 1994): 279292, Valencia.

- (dir.) (1998): 50 años de viaje arqueológico en Valencia. Ajuntament de València. Valencia.

RocA, A. (1998): Los judíos valencianos en la Baja Edad Media. Ajuntament de València. Valencia.

Rodrigo, J. (1913): La judería de Valencia. Editorial ParísValencia. Valencia (edición facsímil, 1992).

SANTANA, I. (1995): De la muerte en Sefarad. La excavación arqueológica en la nueva sede de la Diputación de Sevilla. Diputación de Sevilla, Sevilla.

- (1996): "La excavación arqueológica de urgencia en el cementerio de la Aljama Judía de Sevilla. Aspectos generales". AnuarioArqueológico de Andalucía 92, III: 609-614.

TEIXIDOR, M M.J. (1990): "Les vistes de la ciutat deValència”. EnV. M. Rosselló, M J J. Teixidor, J. Esteban, R. Sicluna, J. F. Mateu, J. M. Palomar, J. Piqueras, J. J. Gregori y F. Palanca: Les vistes valencianes d'Anthonie van den Wijngaerde (1563). Generalitat Valenciana. Valencia: 43-98. 